\title{
GENOTYPIC FREQUENCIES AMONG CLOSE RELATIVES OF PROPOSITI WITH CONDITIONS DETERMINED BY X-RECESSIVE GENES
}

\author{
BY \\ GEORGE KNOX* \\ From the Department of Social Medicine, University of Birmingham
}

The investigation of human abnormalities suspected of possessing genetic determinants demands algebra more complicated than that which may be useful in experimental studies. This is because of the selective effects invoked when we begin with an affected individual and work backwards towards his ancestors and collateral relatives.

In the course of another study the problem arose of the expected genotypic frequencies in the close relatives of children suffering from a condition supposedly determined by an X-recessive gene. Since the results of the necessary deductions may be useful in other population studies of sex-linkage, and since the results do not seem to be available elsewhere, it seemed worthwhile to present them in a separate paper.

\section{(a) Sex Ratio in Propositi}

If an X-recessive gene, $\dot{X}$, has a frequency $g$, then the population frequency of males of the genotype $\dot{X} Y$ is $g$, and of females of genotype $\dot{X} \dot{X}$ it is $g^{2}$. Consequently, the ratio $\mathrm{F} / \mathrm{M}=g^{2} / g=g$, and when the genotypes are fully penetrant or equally penetrant, the sex ratio provides a direct measure of the gene frequency. An alternative expression in these circumstances is that the proportion of females among propositi is $\frac{g}{1+g}$ and of males it is $\frac{1}{1+g}$.

\section{(b) Genotypes of Parents}

\section{THE MOTHER}

Whether the propositus is a boy or a girl we know a gene $\dot{X}$ was received from the mother, who must be either $X \dot{X}$ or $\dot{X} \dot{X}$. The respective population frequencies of these genotypes in women are $2 g(1-g)$

\footnotetext{
* Medical Research Council Clinical Research Fellow.
}

and $g^{2}$. The second genotype, however, has a doubled opportunity of transmitting the gene $\dot{X}$ to any particular child, so the relative frequencies of the two genotypes in mothers of affected children are $2 g(1-g)$ and $2 g^{2}$, and the absolute frequencies are $(1-g)$ and $g$.

\section{THE FATHER}

When the propositus is a girl we know the father is $\dot{X} Y$.

When the propositus is a boy we have no information upon the father's genotype and can presume that the genotypes $X Y$ and $X Y$ occur in the same proportional probabilities as in the population, that is $(1-g)$ and $g$.

If we presume that the sex ratio of propositi is equal to the gene frequency, we may conclude that the fathers' genotypes for all affected children are:

$$
\dot{X} Y=2 g /(1+g) \text {, and } X Y=(1-g) /(1+g) \text {. }
$$

More usefully, perhaps, the frequencies of matingtypes among parents may be stated as in Table I.

TABLE I

MATING TYPE FREQUENCIES

\begin{tabular}{|c|c|c|}
\hline Affected Children & $\begin{array}{l}\text { Parental } \\
\text { Genotypes }\end{array}$ & Frequency \\
\hline Boys & $\begin{array}{l}\dot{X} \dot{X}-\dot{X} Y \\
\dot{X} \dot{X}-X Y \\
X \dot{X}-\dot{X} Y \\
X \dot{X}-X Y\end{array}$ & $\begin{array}{l}g^{2} \\
g(1-g) \\
g(1-g) \\
(1-g)^{2}\end{array}$ \\
\hline Girls & $\begin{array}{l}\mathbf{X} \dot{X}-\dot{X} \mathbf{Y} \\
\mathbf{X X}-\dot{X} \mathbf{Y}\end{array}$ & $\begin{array}{l}g \\
(1-g)\end{array}$ \\
\hline $\begin{array}{l}\text { All Children } \\
\text { (presuming that } \\
\mathbf{F} / \mathbf{M}=\mathbf{g} \text { ) }\end{array}$ & $\begin{array}{l}\dot{X} \mathbf{X}-\dot{X} \mathbf{Y} \\
\dot{X} \mathbf{X}-\mathbf{X Y} \\
\mathbf{X X}-\dot{X} \mathbf{Y} \\
\mathbf{X} \dot{X}-\mathbf{X Y}\end{array}$ & $\begin{array}{l}2 g^{2} /(1+g) \\
g(1-g) /(1+g) \\
2 g(1-g) /(1+g) \\
(1-g)^{2} /(1+g)\end{array}$ \\
\hline
\end{tabular}


TABLE II

Subsequent Siblings of Affected Girls (Method)

\begin{tabular}{|c|c|c|c|c|}
\hline \multicolumn{2}{|c|}{ Parental Mating Combinations } & \multicolumn{2}{|c|}{ Expected Progeny Frequencies } & \multirow{2}{*}{ Genotypes of Subsequent Siblings } \\
\hline Type & Frequency & Of Boys & Of Girls & \\
\hline$\dot{X} \dot{X}-\dot{X} Y \quad .$. & $g$ & $\begin{array}{lll}X Y & \ldots & 0 \\
\dot{X} Y & \ldots & 1\end{array}$ & 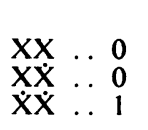 & $\begin{array}{l}\text { Brothers } \\
\quad \begin{array}{l}X Y \\
\dot{X} Y=g \times 0\end{array} \quad(1-g) \times \frac{1}{2}=(1-g) / 2 \\
(1-g) \times \frac{1}{2}=(1-g) / 2\end{array}$ \\
\hline $\mathbf{X X}-\dot{X} Y$ & $(1-g)$ & $\begin{array}{llll}X Y & \ldots & \frac{1}{2} \\
\dot{X} Y & \ldots & \frac{1}{2}\end{array}$ & $\begin{array}{lll}\mathbf{X X} & \cdots & 0 \\
\mathbf{X} & \cdots & \frac{1}{2} \\
\dot{X} \dot{X} & \cdots & \frac{1}{2}\end{array}$ & 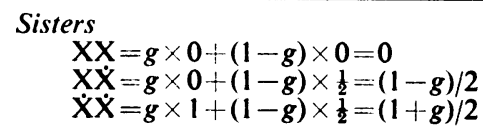 \\
\hline
\end{tabular}

Subsequent Siblings of Bol's

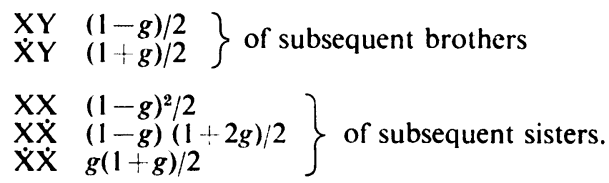

(c) Genotypes of Subsequent Siblings

From the frequencies of parental mating combinations given above together with the expected genotype frequencies in the progeny of each combination, we may deduce the absolute frequencies of different genotypes in subsequent siblings of affected children. The procedure is illustrated fully for affected girls in Table II and the results for boys and for girls + boys are given in the footnotes thereto.

It is interesting to note also that, when two cases of disease occur in each of a series of sibships, the relative proportion of MM, MF, FM, and FF pairs are calculable from the products of the population relative frequencies of the first and the appropriate value for subsequent sibs as given above. This gives:

$$
\begin{aligned}
\mathrm{MM} & =(1+g) / 2 \\
\mathrm{MF}+\mathrm{FM} & =2 g(1+g) / 2 \\
\mathrm{FF} & =g(1+g) / 2 .
\end{aligned}
$$

From this the absolute frequencies of pairs of the three types are:

$$
\begin{aligned}
\mathrm{MM} & =1 /(1+3 g) \\
\mathrm{MF}+\mathrm{FM} & =2 g /(1+3 \dot{g}) \\
\mathrm{FF} & =g /(1+3 g) .
\end{aligned}
$$

It is clear from this that, in sex-linked inheritance with equal penetrance in the two sexes, the ratio $(F M+M F) / F F$ is 2 at all gene frequencies and that the ratio $F F / M M$ is equal to $g$. An alternative estimator of $g$, using all the pair-data, is

$$
(F M+M F+F F) / 3 M M \text {. }
$$

$$
\begin{aligned}
& \text { Subsequent Siblings of all Propositi } \\
& \text { (presuming that } \mathrm{F} / \mathrm{M}=\mathrm{g} \text { ) } \\
& \left.\begin{array}{rl}
\mathrm{XY} & =(1-g) / 2 \\
\dot{\mathrm{X}} \mathrm{Y} & =(1+g) / 2
\end{array}\right\} \text { of subsequent brothers } \\
& \mathrm{XX}=(1-g)^{2} / 2(1+g) \\
& \left.\begin{array}{l}
X X=(1-g)^{2} / 2(1+g) \\
X \dot{X}=(1-g)(1+3 g) / 2(1+g) \\
\dot{X} \dot{X}=g
\end{array}\right\} \text { of subsequent sisters. }
\end{aligned}
$$

\section{(d) Genotypes of Maternal Grandparents}

We have seen that the mother of an affected child of either seX is $\mathrm{X} \dot{X}$ on $(1-g)$ occasions and $\dot{X} \dot{X}$ on $g$ occasions.

When she is $\dot{X} \dot{X}$, the reasoning given under $(b)$ can be re-applied; the probability of her parents

\begin{tabular}{|c|c|c|}
\hline Genotype & $\begin{array}{l}\text { Absolute Popula- } \\
\text { tion Frequencies }\end{array}$ & $\begin{array}{l}\text { Relative Popula- } \\
\text { tion Frequencies }\end{array}$ \\
\hline $\begin{array}{l}\dot{X} \dot{X}-\mathbf{X Y} \\
\mathbf{X X}-\dot{X Y} \\
\dot{X} \dot{X}-\dot{X} Y \\
\dot{X X}-\dot{X} Y\end{array}$ & $\begin{array}{l}g^{2}(1-g) \\
2 g(1-g)^{2} \\
2 g^{2}(1-g) \\
g(1-g)^{2}\end{array}$ & $\begin{array}{c}g \\
2(1-g) \\
2 g \\
(1-g)\end{array}$ \\
\hline
\end{tabular}
being $\dot{X} \dot{X}-\dot{X} Y$ is $g$, and of their being $X \dot{X}-\dot{X} Y$ is $(1-g)$, no other combinations being possible. Thus, the probability that an affected child will have an $\dot{\mathrm{X}} \dot{\mathrm{X}}$ mother with maternal grandparents $\dot{\mathrm{X}} \dot{\mathrm{X}}-\dot{\mathrm{X}} \mathbf{Y}$ is $g^{2}$, and an $\dot{X} \dot{X}$ mother with maternal grandparents $\mathrm{X} \dot{\mathrm{X}}-\dot{\mathrm{X}} \mathrm{Y}$ is $g(1-g)$.

When she is $\mathrm{X} \dot{\mathrm{X}}$ her own parents may be as shown in Table III.

TABLE III

PARENTS OF AN $\dot{X} \dot{X}$ MOTHER

However, the first and last of these combinations have twice the chance of the others of transmitting the genotype $\dot{X} X$ to any particular daughter, so that the relative frequencies among parents of $X \dot{X}$ women become $g,(1-g), g,(1-g)$, respectively, and the absolute frequencies are half these values. The probability of an affected child having an XXं mother and grandparents of these types are the products of these last (halved) values with $(1-g)$. 
Since we may not be able to distinguish between $\mathrm{X} \dot{\mathrm{X}}$ and $\dot{\mathrm{X}} \dot{\mathrm{X}}$ mothers we may add these results together in the appropriate proportions. The resulting frequencies for maternal grandparents mating types are then as follows:

$$
\begin{aligned}
& \text { Mating Type Frequency } \\
& \dot{X} \dot{X}-\dot{X} Y \\
& \dot{X} \dot{X}-X Y \\
& \mathbf{X X}-\dot{X} Y \\
& \mathbf{X X}-\mathbf{X Y} \\
& \mathbf{X X}-\dot{X} Y \\
& g^{2} \\
& 3 g(1-g) / 2 \\
& (1-g)^{2} / 2 \\
& (1-g)^{2} / 2 \text {. }
\end{aligned}
$$

\section{(e) Genotypes of Maternal Aunts and UnCles}

- Proceeding in a manner analagous with the reasoning under $(c)$, multiplying expected progeny frequencies by the above frequencies of grandparental

\begin{tabular}{|c|c|c|}
\hline & Frequency \\
\hline \multicolumn{2}{|c|}{$\begin{array}{l}\text { Mating Type } \\
\dot{\mathrm{X}} \dot{\mathrm{X}} \dot{\mathrm{X}}\end{array}$} & $g^{2}(1+3 g) / 4$ \\
\hline & $\dot{X} Y$ & $2 g(1-g)(1-3 g) / 4$ \\
\hline & $\mathbf{X Y Y}$ & $(1-g)^{2}(1+3 g) / 4$ \\
\hline & $X Y$ & $3 g^{2}(1-g) / 4$ \\
\hline & $\begin{array}{l}X Y \\
X Y\end{array}$ & $\begin{array}{l}6 g(1-g)^{2} / 4 \\
3(1-g)^{3} / 4 .\end{array}$ \\
\hline
\end{tabular}
mating-types, we may obtain the genotype frequencies in maternal aunts and uncles. These are:

$$
\begin{aligned}
& \left.\begin{array}{l}
X Y=3(1-g) / 4 \\
\dot{X} Y=(1+3 g) / 4
\end{array}\right\} \text { of maternal uncles }
\end{aligned}
$$

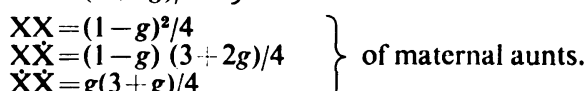

This is the same whether the propositus is a boy or a girl.

\section{( $f$ ) Genotypes of Maternal Cousins}

Maternal uncles will engage in marriages of the following types and frequencies:

By applying expected progeny ratios for these matings, we expect the following genotypic frequencies among their offspring (i.e. cousins of propositi):

$$
\begin{aligned}
& \left.\begin{array}{l}
X Y=(1-g) \\
\dot{X} Y=g
\end{array}\right\} \text { of sons of maternal uncles } \\
& \left.\begin{array}{l}
X X=3(1-g)^{2} / 4 \\
X \dot{X}=(1-g)(1+6 g) / 4
\end{array}\right\} \begin{array}{l}
\text { of daughters of } \\
\text { maternal uncles. }
\end{array}
\end{aligned}
$$

Maternal aunts will engage in the same six types of marriages but with frequencies:

$\begin{array}{cl}\text { Mating Type } & \text { Frequency } \\ \text { XX XY } & \begin{array}{l}g(3+g) / 4 \\ \text { XX XY }\end{array} \\ \text { XX X XY } & g(1-g)(3+2 g) / 4 \\ \text { XX XY XY } & g(1-g)(3+g) / 4 \\ \text { XX XY } & (1-g)^{2}(3+2 g) / 4 \\ \text { XX XY } & (1-g)^{3} / 4 .\end{array}$

In the same way as for maternal uncles we may deduce the genotype frequencies in the offspring of the maternal aunts as follows:

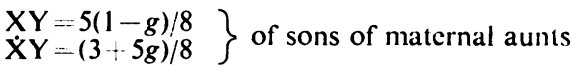

$$
\begin{aligned}
& \left.\begin{array}{l}
X X=5(1-g)^{2} / 8 \\
X \dot{X}=(3+10 g)(1-g) / 8 \\
\dot{X} \dot{X}=g(3+5 g) ; 8
\end{array}\right\} \begin{array}{l}
\text { of daughters of matcrnal } \\
\text { aunts. }
\end{array}
\end{aligned}
$$

Maternal cousins of all kinds, via uncles or aunts, are distributed as follows:

$$
\begin{aligned}
& \left.\begin{array}{rl}
X Y & =13(1-g) / 16 \\
\dot{X} Y & =(3+13 g) / 16
\end{array}\right\} \text { of all male maternal cousins } \\
& \left.\begin{array}{l}
X \dot{X}=11(1-g)^{2} / 16 \\
X \dot{X}=(1-g)(5+22 g)_{i}^{\prime} 16 \\
\dot{X} \dot{X}=g(5+11 g)_{i} / 16
\end{array}\right\} \begin{array}{l}
\text { of all female maternal } \\
\text { cousins. }
\end{array}
\end{aligned}
$$

All the values given in this section are the same for male propositi as for females.

\section{( $g$ ) Genotypes of Paternal Grandparents}

On the $1 /(1+g)$ occasions when the propositus is male, the genotypes of paternal grandparents may be taken as representative of the population as a whole, and the various pair combinations likewise, that is:

$$
\begin{array}{cl}
\text { Mating Type } & \text { Frequency } \\
\dot{X} \dot{X}-\dot{X} Y & g^{3} \\
\text { X }-\dot{X} Y & 2 g^{2}(1-g) \\
\text { XX-XY } & g(1-g)^{2} \\
\dot{X} \dot{X}-X Y & g^{2}(1-g) \\
\text { XX } \mathbf{X} Y & 2 g(1-g)^{2} \\
\text { XX }-X Y & (1-g)^{3}
\end{array}
$$

... and all aunts, uncles, and cousins in these families may be regarded as being distributed as in the normal population, that is:

$$
\begin{aligned}
& \left.\begin{array}{l}
X Y=(1-g) \\
\dot{X} Y=g
\end{array}\right\} \text { of all males }
\end{aligned}
$$

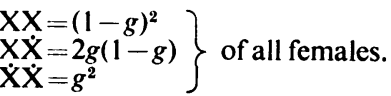

On the $g /(1+g)$ occasions when the propositus is female, we know that the father is $\dot{X} Y$; in this event the same argument applies to the paternal grandparents as was applied to the parental genotypes of male propositi under $(b)$. Thus, the combination frequencies of the paternal grandparents of female propositi are:

$$
\begin{aligned}
& \dot{X} \dot{X}-\dot{X} Y=g^{2} \\
& \dot{X} \dot{X}-X Y=g(1-g) \\
& X \dot{X}-\dot{X} Y=g(1-g) \\
& X \dot{X}-X Y=(1-g)^{2}(i . e . \text { as the parents of affec-. } \\
&\text { ted boys. See }(b)) .
\end{aligned}
$$


If we fail to distinguish between male and female propositi and presume that the $F / M$ ratio $=g$, the genotypes of all paternal grandparents are:

\begin{tabular}{|c|c|}
\hline Mating Type & Frequency \\
\hline$-\dot{X} Y$ & $2 g^{3} /(1+g)$ \\
\hline $\mathbf{X} \dot{X}-\dot{X} Y$ & $3 g^{2}(1-g) /(1+g)$ \\
\hline$X X-X Y$ & $g(1-g)^{2} /(1+g)$ \\
\hline$\dot{X} \mathbf{X}-X Y$ & $2 g^{2}(1-g) /(1+g)$ \\
\hline$-X Y$ & $3 g(1-g)^{2} /(1+g)$ \\
\hline$X Y$ & $(1-g)^{3} /(1+g)$ \\
\hline
\end{tabular}

\section{(h) Genotypes of Paternal Aunts and Uncles}

Paternal uncles and aunts of male propositi have genotype frequencies equal to those in the population.

The paternal uncles and aunts of female propositi have genotype frequencies calculable from the frequency of mating types in the paternal grandparents (see $(g))$. The genotypes of these uncles and aunts are the same as for later sibs of male propositi, (sce $(b))$ namely:

$$
\begin{aligned}
& X Y=(1-g) / 2 \quad \text { of paternal uncles of female } \\
& \dot{X} Y=(1+g) / 2\} \text { propositi }
\end{aligned}
$$

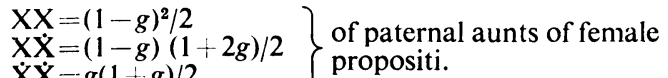

$$
\begin{aligned}
& \dot{X} \dot{X}=g(1+g) / 2 \quad\} \text { propositi. }
\end{aligned}
$$

The distribution for all paternal aunts and uncles, irrespective of the sex of the propositus, and presuming $\mathrm{F} / \mathrm{M}=\mathrm{g}$, is:

$$
\begin{aligned}
& \left.\begin{array}{l}
X Y=(2+g)(1-g) / 2(1+g) \\
\dot{X} Y=g(3+g) / 2(1+g)
\end{array}\right\} \text { of all paternal uncles } \\
& \left.\begin{array}{l}
X X=(2+g)(1-g)^{2} / 2(1+g) \\
X \dot{X}=g(1-g)(5+2 g) / 2(1+g) \\
\dot{X} \dot{X}-g^{2}(3+g) / 2(1+g)
\end{array}\right\} \begin{array}{l}
\text { of all paternal } \\
\text { aunts. }
\end{array}
\end{aligned}
$$

\section{(i) Genotypes of Paternal Cousins}

Paternal cousins of male propositi have genotype frequencies equal to those in the population (see $(g))$.

Paternal cousins of female propositi have genotype frequencies based upon the frequency of mating

\begin{tabular}{|c|c|c|}
\hline & Mating Type & Frequency \\
\hline $\begin{array}{c}\text { For Paternal } \\
\text { Uncles of } \\
\text { Females }\end{array}$ & $\begin{array}{l}\dot{X} \dot{X}-\dot{X} Y \\
X \dot{X}-\dot{X} Y \\
X X-\dot{X} Y \\
\dot{X} \dot{X}-\dot{X Y Y} \\
X \dot{X}-\dot{X Y Y} \\
X X-X Y\end{array}$ & $\begin{array}{l}g^{2}(1+g) / 2 \\
2 g(1-g)(1+g) / 2 \\
(1-g)^{2}(1+g) / 2 \\
g^{2}(1-g) / 2 \\
2 g(1-g)^{2} / 2 \\
(1-g)^{3} / 2\end{array}$ \\
\hline $\begin{array}{c}\text { For Paternal } \\
\text { Aunts of } \\
\text { Females }\end{array}$ & $\begin{array}{l}\dot{X} \dot{X}-\dot{X} Y \\
\dot{X}-\dot{X} Y \\
X X-\dot{X Y Y} \\
\dot{X} \dot{X}-\dot{X Y} \\
X \dot{X}-\mathbf{X Y} \\
X X-X Y\end{array}$ & $\begin{array}{l}g^{2}(1+g) / 2 \\
g(1-g)(1+2 g) / 2 \\
g(1-g)^{2} / 2 \\
g(1+g)(1-g) / 2 \\
(1-g)^{2}(1+2 g) / 2 \\
(1-g)^{3} / 2\end{array}$ \\
\hline
\end{tabular}
types entered into by uncles and aunts of genotype frequencies given under $(h)$. These mating frequencies are as follows:

\begin{tabular}{ccl} 
& MatingType & \multicolumn{1}{c}{ Frequency } \\
For All Paternal & $\dot{\mathrm{X}} \dot{\mathrm{X}}-\dot{\mathrm{X} Y}$ & $g^{2}(1+g) / 2$ \\
Aunts and & $\mathrm{X} \dot{\mathrm{X}}-\dot{\mathrm{X} Y}$ & $g(1-g)(3+4 g) / 4$ \\
Uncles of & $\mathrm{XX}-\dot{\mathrm{X} Y}$ & $(1+2 g)(1-g)^{2} / 4$ \\
Females & $\dot{\mathrm{X}}-\mathrm{XY}$ & $g(1-g)(1+2 g) / 4$ \\
& $\mathrm{X} \dot{\mathrm{X}}-\mathrm{XY}$ & $(1+4 g)(1-g)^{2} / 4$ \\
& $\mathrm{XX}-\mathrm{XY}$ & $(1-g)^{3} / 2$ \\
For All Paternal & $\dot{\mathrm{X}} \mathrm{X}-\dot{\mathrm{X} Y}$ & $g^{3}(3+g) / 2(1+g)$ \\
Aunts and & $\mathrm{X} \dot{\mathrm{X}}-\dot{\mathrm{X} Y}$ & $g^{2}(1-g)(11+4 g) / 4(1-g)$ \\
Uncles of All & $\mathrm{XX}-\dot{\mathrm{X} Y}$ & $g(1-g)^{2}(5+2 g) / 4(1+g)$ \\
Propositi when & $\dot{\mathrm{X}} \mathrm{X}-\mathrm{XY}$ & $g^{2}(1-g)(5+2 g) / 4(1+g)$ \\
$\mathrm{F} / \mathrm{M}=g$ & $\mathrm{XX}-\mathrm{XY}$ & $g(1-g)^{2}(9+4 g) / 4(1+g)$ \\
& $\mathrm{XX}-\mathrm{XY}$ & $(1-g)^{3}(2+g) / 2(1+g)$.
\end{tabular}

From these formulae, by a variety of routes, the genotypes of paternal cousins may be deduced:

Children of $\quad X Y=(1-g) \quad\}$ of sons of paternal Paternal Uncles $\dot{X} Y=g \quad\}$ uncles of females

of Females $\left.\quad \mathrm{XX}=(1-g)^{2} / 2 \quad\right)$ of daughters $\dot{\mathrm{X}} \dot{\mathrm{X}}=(1-g)(1+2 g) / 2\}$ of paternal $\dot{\mathrm{X}} \dot{\mathrm{X}}=g(1+g) / 2\}$ uncles of females

(Note: The boy cousins here are distributed as in the normal population. The girl cousins are similar to the later sisters of male propositi (c) and to the paternal aunts of female propositi. The paternal aunts of female propositi are also the paternal aunts of the girl cousins themselves.)

Children of $\quad X Y=3(1-g) / 4\}$ of sons of paternal Paternal Aunts $\dot{\mathrm{X} Y}=(1+3 g) / 4\}$ aunts of females of Females

$$
\left.\begin{array}{l}
\mathrm{XX}=3(1-g)^{2} / 4 \\
\mathrm{XX}=(1-g)(1-6 g) / 4) \\
\dot{X} \dot{X}=g(1+3 g) / 4
\end{array}\right\} \begin{aligned}
& \text { of daughters } \\
& \text { of paternal } \\
& \text { aunts of fe- } \\
& \text { males }
\end{aligned}
$$

All Paternal $\quad \mathrm{XY}=7(1-g) / 8\}$ of sons of paternal Cousins of $\dot{X} Y=(1+7 g) / 8\}$ aunts and uncles of Females females

$$
\begin{aligned}
& \left.X X=5(1-g)^{2} / 8 \quad\right\} \text { of daughters } \\
& \left.\begin{array}{l}
X \dot{X}=(1-g)(3+10 g) / 8 \\
\dot{X} \dot{X}=g(3+5 g) / 8
\end{array}\right\} \begin{array}{l}
\text { of paternal } \\
\text { aunts and }
\end{array} \\
& \text { uncles of } \\
& \text { females }
\end{aligned}
$$

Children of Paternal Uncles of All Propositi when $\mathrm{F} / \mathrm{M}=\mathrm{g}$

$\left.\begin{array}{l}X Y-1-g \\ \dot{X} Y-g\end{array}\right\}$ of sons of all paternal uncles

$\left.\mathrm{XX}=(2 \div g)(1-g)^{2} / 2(1 ; g)\right)$ of daughters of

$\left.\begin{array}{l}\mathrm{X} \dot{\mathrm{X}}-g(1-g)(5-2 g) / 2(1+g) \\ \dot{\mathrm{X}}-g^{2}(3+g) / 2(1+g)\end{array}\right\} \begin{aligned} & \text { of daughters of } \\ & \text { all paternal uncles }\end{aligned}$

Children of Paternal Aunts of All Propositi when $\mathrm{F} / \mathrm{M}-\mathrm{g}$

$X Y=-(1-g)(4+3 g) / 4(1+g)\}$ of sons of all $\dot{X} Y-g(5+3 g) / 4(1+g) \quad\}$ paternal aunts

XX $\left.-(4-3 g)(1-g)^{2} / 4(1-g)\right)$ of daughters of

XX $3 g(1-g)(3-2 g) / 4(1+g)\}$ all paternal

$\left.\dot{\mathrm{X}} \dot{\mathrm{X}}-g^{2}(5+3 g) / 4(1+g) \quad\right\}$ aunts

All Paternal Cousins of All Propositi when $\mathrm{F} / \mathrm{M}=\mathrm{g}$

$X Y=(1-g)(8+7 g) / 8(1+g)\}$ of all male cousins

$\dot{X} Y-g(9+7 g) / 8(1+g) \quad\}$ of all propositi

$\left.\mathrm{XX}-(1-g)^{2}(8+5 g) / 8(1+g)\right\}$ of all female

$X \dot{X}=g(1-g)(19+10 g) / 8(1+g)\}$ cousins of all

$\left.\dot{\mathrm{X}} \dot{\mathrm{X}}-g^{2}(11+5 g) / 8(1+g) \quad\right\}$ propositi. 


\section{(j) EXAMPLes}

Several worked examples of the application of these formulae are given in Table IV. It is shown there that, at the upper limit of $g$, all the formulae resolve into the same values. It will be sufficiently clear at what steps the combination of data for male and female propositi depends upon the assumption that $\mathrm{F} / \mathrm{M}=\mathrm{g}$ and when the combination of data related to aunts and uncles depends upon the assumption that both occur in equal numbers. It is also implicit in the construction that major selective effects (for example the death of males) have not distorted the picture, and mutations have not been taken into account.

\section{SUMMARY}

The algebraic implications of sex-linked transmission are explored from the point of view that propositi have been selected and the genotypic frequencies in relatives are to be deduced. Formulae are presented for the expected frequencies in relatives. Some numerical examples are also given.

TABLE IV

TABULATED FREQUENCIES OF GENOTYPES OF MAIN RELATIVES OF PROPOSITI AT DIFFERENT VALUES OF $g$

\begin{tabular}{|c|c|c|c|c|c|c|c|c|c|}
\hline \multirow{2}{*}{\multicolumn{3}{|c|}{ Relative }} & \multirow{2}{*}{ Sex of Propositus } & \multirow{2}{*}{ Genotype } & \multicolumn{5}{|c|}{$g$} \\
\hline & & & & & Nr. $0 \cdot 0$ & $0 \cdot 1$ & $0 \cdot 2$ & 0.5 & $\mathrm{Nr} 1 \cdot 0$ \\
\hline Later Sibs & .. & . & $\mathbf{M}$ & $\begin{array}{l}\underset{\mathbf{X Y}}{\mathbf{X}} \\
\underset{\mathbf{X}}{\mathbf{X}} \\
\mathbf{X} \mathbf{X} \\
\dot{\mathbf{X}} \\
\dot{\mathbf{X}}\end{array}$ & $\begin{array}{l}0.5 \\
0.5 \\
0 \cdot 5 \\
0.5 \\
0.0\end{array}$ & $\begin{array}{l}0.45 \\
0.55 \\
0.405 \\
0.54 \\
0.055\end{array}$ & $\begin{array}{l}0.4 \\
0.6 \\
0.32 \\
0.56 \\
0.12\end{array}$ & $\begin{array}{l}0.25 \\
0.75 \\
0.125 \\
0.5 \\
0.375\end{array}$ & $\begin{array}{l}0.0 \\
1.0 \\
0.0 \\
0.0 \\
1.0\end{array}$ \\
\hline Later Sibs & $\cdots$ & . & $\mathbf{F}$ & $\begin{array}{l}\mathbf{X Y} \\
\dot{\mathbf{X}} \mathbf{Y} \\
\mathbf{X} \mathbf{X} \\
\mathbf{X} \\
\dot{\mathbf{X}} \mathbf{X} \\
\end{array}$ & $\begin{array}{l}0.5 \\
0.5 \\
0.0 \\
0.5 \\
0.5 \\
\end{array}$ & $\begin{array}{l}0.45 \\
0.55 \\
0.0 \\
0.45 \\
0.55 \\
\end{array}$ & $\begin{array}{l}0.4 \\
0.6 \\
0.0 \\
0.4 \\
0.6 \\
\end{array}$ & $\begin{array}{l}0.25 \\
0.75 \\
0.0 \\
0.25 \\
0.75 \\
\end{array}$ & $\begin{array}{l}0.0 \\
1.0 \\
0.0 \\
0.0 \\
1.0 \\
\end{array}$ \\
\hline Later Sibs & $\cdots$ & . & $\mathbf{M}+\mathbf{F}(\mathbf{F} / \mathbf{M}=g)$ & $\begin{array}{l}\underset{\mathbf{X} Y}{\mathbf{X}} \\
\mathbf{X} \mathbf{X} \\
\dot{\mathbf{X}} \\
\dot{\mathbf{X}} \\
\mathbf{X}\end{array}$ & $\begin{array}{l}0.5 \\
0.5 \\
0.5 \\
0.5 \\
0.0\end{array}$ & $\begin{array}{l}0.45 \\
0.55 \\
0.368 \\
0.532 \\
0.1\end{array}$ & $\begin{array}{l}0.4 \\
0.6 \\
0.267 \\
0.533 \\
0.2\end{array}$ & $\begin{array}{l}0.25 \\
0.75 \\
0.083 \\
0.417 \\
0.5\end{array}$ & $\begin{array}{l}0.0 \\
1.0 \\
0.0 \\
0.0 \\
1.0\end{array}$ \\
\hline Maternal Uncles and & Aunts & $\cdots$ & $\mathbf{M}$ or $\mathbf{F}$ or $\mathbf{M}+\mathbf{F}$ & $\begin{array}{l}\mathbf{X} \mathbf{X} \\
\mathbf{X} \mathbf{Y} \\
\mathbf{X} \mathbf{X} \\
\mathbf{X} \dot{\mathbf{X}} \\
\dot{\mathbf{X}}\end{array}$ & $\begin{array}{l}0.75 \\
0.25 \\
0.25 \\
0.75 \\
0.0\end{array}$ & $\begin{array}{l}0.675 \\
0.325 \\
0.202 \\
0.72 \\
0.077\end{array}$ & $\begin{array}{l}0.6 \\
0.4 \\
0.16 \\
0.68 \\
0.16\end{array}$ & $\begin{array}{l}0.375 \\
0.625 \\
0.062 \\
0.5 \\
0.437\end{array}$ & $\begin{array}{l}0.0 \\
1.0 \\
0.0 \\
0.0 \\
1.0\end{array}$ \\
\hline Maternal Cousins & . & $\cdots$ & $\mathbf{M}$ or $\mathbf{F}$ or $\mathbf{M}+\mathbf{F}$ & $\begin{array}{l}\underset{\mathbf{X} Y}{\mathbf{X}} \\
\underset{\mathbf{X}}{\mathbf{X}} \\
\dot{\mathbf{X}} \\
\dot{\mathbf{X}}\end{array}$ & $\begin{array}{l}0.813 \\
0.187 \\
0.687 \\
0.313 \\
0.0\end{array}$ & $\begin{array}{l}0.732 \\
0.269 \\
0.557 \\
0.405 \\
0.038\end{array}$ & $\begin{array}{l}0.65 \\
0.35 \\
0.44 \\
0.47 \\
0.09\end{array}$ & $\begin{array}{l}0 \cdot 406 \\
0 \cdot 594 \\
0 \cdot 172 \\
0 \cdot 5 \\
0 \cdot 328\end{array}$ & $\begin{array}{l}0.0 \\
1.0 \\
0.0 \\
0.0 \\
1.0\end{array}$ \\
\hline Paternal Uncles and & Aunts & $\cdots$ & $\mathbf{F}$ & $\begin{array}{l}\underset{\mathbf{X Y}}{\mathbf{X Y}} \\
\underset{\mathbf{X}}{\mathbf{X}} \\
\dot{\mathbf{X}} \\
\dot{\mathbf{X}}\end{array}$ & $\begin{array}{l}0.5 \\
0.5 \\
0.5 \\
0.5 \\
0.0 \\
\end{array}$ & $\begin{array}{l}0.45 \\
0.55 \\
0.405 \\
0.54 \\
0.055 \\
\end{array}$ & $\begin{array}{l}0.4 \\
0.6 \\
0.32 \\
0.56 \\
0.12 \\
\end{array}$ & $\begin{array}{l}0 \cdot 25 \\
0 \cdot 75 \\
0 \cdot 125 \\
0 \cdot 5 \\
0 \cdot 375 \\
\end{array}$ & $\begin{array}{l}0.0 \\
1.0 \\
0.0 \\
0.0 \\
1.0\end{array}$ \\
\hline Paternal Uncles and & Aunts & .. & $M+F(F / M=g)$ & $\begin{array}{l}\mathbf{X Y} \\
\mathbf{X} \mathbf{X} \\
\mathbf{X} \mathbf{X} \\
\mathbf{X} \\
\dot{X} \\
\dot{X} \\
\mathbf{X}\end{array}$ & $\begin{array}{l}1 \cdot 0 \\
0.0 \\
1.0 \\
0.0 \\
0.0 \\
\end{array}$ & $\begin{array}{l}0.859 \\
0.141 \\
0.773 \\
0.213 \\
0.014 \\
\end{array}$ & $\begin{array}{l}0.733 \\
0.267 \\
0.587 \\
0.36 \\
0.053 \\
\end{array}$ & $\begin{array}{l}0.417 \\
0.583 \\
0.208 \\
0.5 \\
0.292 \\
\end{array}$ & $\begin{array}{l}0.0 \\
1.0 \\
0.0 \\
0.0 \\
1.0\end{array}$ \\
\hline Paternal Cousins & $\cdots$ & . & $\mathbf{F}$ & $\begin{array}{l}\underset{\mathbf{X} Y}{\mathbf{X}} \\
\mathbf{X} \mathbf{X} \\
\mathbf{X} \\
\dot{\mathbf{X}} \\
\dot{\mathbf{X}} \\
\end{array}$ & $\begin{array}{l}0.875 \\
0.125 \\
0.625 \\
0.375 \\
0.0 \\
\end{array}$ & $\begin{array}{l}0.788 \\
0.212 \\
0.506 \\
0.45 \\
0.044 \\
\end{array}$ & $\begin{array}{l}0.7 \\
0.3 \\
0.4 \\
0.5 \\
0.1 \\
\end{array}$ & $\begin{array}{l}0.437 \\
0.563 \\
0.156 \\
0.5 \\
0.344 \\
\end{array}$ & $\begin{array}{l}0.0 \\
1.0 \\
0.0 \\
0.0 \\
1.0 \\
\end{array}$ \\
\hline Paternal Cousins & $\cdots$ & . & $M+F(F / M=g)$ & $\begin{array}{l}\underset{\mathbf{X Y}}{\mathbf{X Y}} \\
\mathbf{X} \mathbf{X} \\
\mathbf{X} \\
\dot{X} \mathbf{X} \\
\mathbf{X}\end{array}$ & $\begin{array}{l}1 \cdot 0 \\
0 \cdot 0 \\
1 \cdot 0 \\
0 \cdot 0 \\
0 \cdot 0\end{array}$ & $\begin{array}{l}0.89 \\
0.11 \\
0.782 \\
0.205 \\
0.013\end{array}$ & $\begin{array}{l}0 \cdot 783 \\
0.217 \\
0.6 \\
0 \cdot 35 \\
0.05\end{array}$ & $\begin{array}{l}0.479 \\
0.521 \\
0.219 \\
0.5 \\
0.281\end{array}$ & $\begin{array}{l}0.0 \\
1.0 \\
0.0 \\
0.0 \\
1.0\end{array}$ \\
\hline
\end{tabular}

The frequencies in this Table refer to $1 \cdot 0=$ Total individuals of the same sex 